\title{
Estimating Sizing and Location of Shunt Compensation using Load Shedding
}

\author{
Ahmed M. H. AL-Yousif \\ Department of Electrical Engineering \\ Engineering College \\ Mosul University \\ Mosul, Iraq
}

\begin{abstract}
This research paper focuses on estimating the sizing and location of shunt compensation based on load shedding approach applied to IEEE 5 Bus system using MATLAB. Since power system networks, especially the transmission lines systems have been recently operated under highly stressed conditions which in turn had led to make the load bus voltages below the permissible value, hence when a line suffers from an outage for any reason, then a decrease in voltages of one or more loads due to the inability of the other lines to meet the requirements of such loads (particularly inductive loads) may occur. In this research work an estimating method was proposed to determine the size and the amount of the reactive power required to support the bus voltage at the associated load bus whenever a line outage occurs, by identifying the weak bus required shunt compensation based on load shedding. The power deficit at the load buses (characterized by low voltage levels due to the system's inability to meet the load requirement) have been tackled alternatively through the process of shunt compensation. Partial load shedding was suggested in certain proportions for the purpose of estimating the size of reactive power required to support the voltages at the weak load bus and therefore to impede the power deficit resulting from the outage of a line.
\end{abstract}

\section{Keywords}

Load Shedding, Weak bus, Critical line, Shunt compensation, Voltage performance index.

\section{INTRODUCTION}

Power systems were recently pushed to operate closer to their stability limits due to the fact that load demands keep increasing while the transmission systems expansion plans are comparatively slow, and hence forcing a line or more than one line to be in outage condition. Shunt compensation can be adopted as a control action aiming to avoid system collapse [1]. Load shedding which is defined as an amount of load that must almost instantly be removed from a power system to keep the remaining portion of the system operating as stable as required [2], can thus be applied with its main objective to assist the power system to maintain its stability by keeping the balance between supply and demand. Load shedding involves reducing the consumption by specific amounts through the process of partial turning off the critical bus electricity supply.

This research work is based on Under-Voltage Load Shedding (UVLS) principle of electric power systems which is frequently used against Voltage Collapse [3]. Load shedding may be done both automatically and manually, depending on whether the disconnections are performed immediately (automatically based on frequency measurements) or it is a planned load shedding (manually) [4].
Voltage instability is a major concern in power system operation since it is well known that voltage instability and voltage collapse may lead to blackout condition or abnormally low voltages in a significant part of the power system [5].

\section{VOLTAGE PERFORMANCE INDEX (PIV)}

Electric apparent power (in 'volt-amperes' units) is composed of both active power and reactive power where active power plays its vital role to maintain power system frequency at the required stable and secure levels, while reactive power plays its vital role to maintain the power system voltage at all the buses around the nominal value. Keeping transmission level voltages at nominal value or within a tight range would ensure proper voltages at the suitable levels. Power system equipment are designed to operate within a voltage range usually within $\pm 5 \%$ of the nominal value. At low voltages, the performance of most of the electrical equipment is poor [6]. The gradual change in power system leads to reactive power shortage resulting in reducing power system stability. When a critical line suffers from an outage, power flow would be increased in some other lines and there would be a corresponding voltage decrease at the bus which leads to shortage of reactive power.

As the critical point is reached, heavy reactive power losses lead to a high voltage drop and voltage collapse may take place. To prevent the system from reaching this situation, there would be no any other choices except the options of either to augment reactive power support or to cut-off reactive power demand. The method to overcome voltage collapse lies in placing reactive power support at the weakest bus having lowest margin or near the collapse point [7]. Voltage performance index $\left(\mathrm{PI}_{\mathrm{V}}\right)$ would hence be required to check voltages at all buses in the network against their respective limits for each line outage. Generally, a margin of the permissible limits would be in the range of $\pm 5 \%$, i.e., 0.95 p.u. for minimum voltage and 1.05 for maximum [8].

The $\mathrm{PI}_{\mathrm{V}}$ ranking is done in the descending order according to its value to discriminate the critical states which having $\mathrm{PI}_{V}$ values greater than "1", to give planners a very quick list of "worst case" states and then indicating the weak bus [9]. The general expression of $\mathrm{PI}_{\mathrm{V}}$ in p.u. for maximum voltage is given by:

$\mathrm{PI}_{\mathrm{V}}=\sum_{\mathrm{i}=1}^{\mathrm{NB}} \frac{\mathrm{W}_{\mathrm{Vi}}}{2 \mathrm{n}}\left(\frac{\left|\mathrm{V}_{\mathrm{i}}\right|-\left|\mathrm{V}_{\mathrm{i}}^{\mathrm{SP}}\right|}{\Delta \mathrm{V}_{\mathrm{i}}^{\mathrm{Lim}}}\right)^{2 \mathrm{n}}$

Where:

NB: is the number of buses in the system. 
$\mathrm{W}_{\mathrm{Vi}}$ is the real non-negative weighting factor which is equal to 1 in this equation.

$\mathrm{n}$ : is the exponent of penalty function ( $\mathrm{n}=1$ is preferred).

$\left|V_{i}\right|$ : is the voltage magnitude at bus $i$.

$\left|\mathrm{V}_{\mathrm{i}}^{\mathrm{sp}}\right|$ is the specified (rated) voltage magnitude at bus i.

$\Delta \mathrm{V}_{\mathrm{i}}^{\mathrm{Lim}} \mid$ deviations are unacceptable [10].

\section{VOLTAGE AND REACTIVE POWER CONTROL}

If the system is unstable, then, it is necessary to determine what action should be taken to bring the it back to the stable state [11]. This situation becomes worse in the absence of reactive power support required to maintain normal voltage profiles at the receiving end buses. Reactive power compensation would thus be necessary to make the system more stable [12]. Shunt compensation techniques is used to support voltage security by regulating the voltage at a weak bus-bar against load variations. Figure (1) shows a single-line diagram of an uncompensated transmission line while, figure (2) gives a single diagram of a compensated transmission line [13].

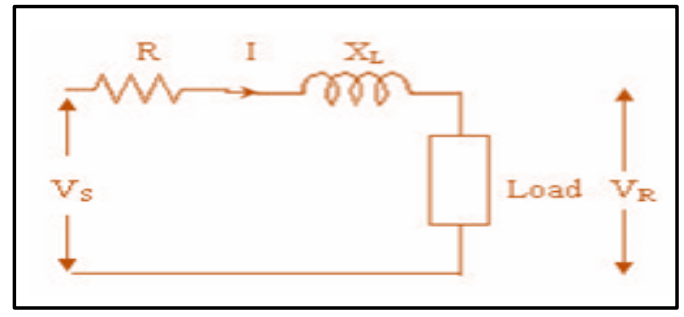

Fig 1: Uncompensated Single-line Diagram of a Transmission Line

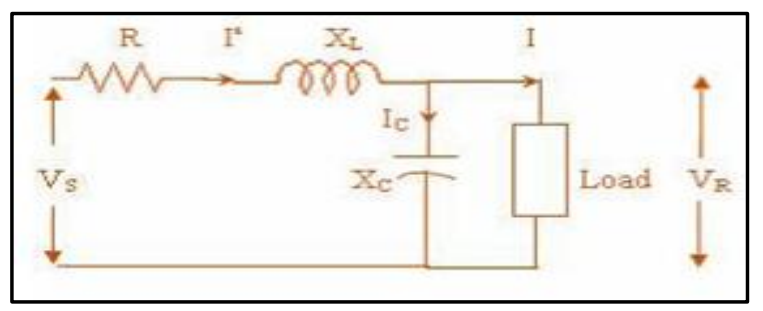

Fig 2: Compensated Single-line Diagram of a Transmission Line

\section{SIMULATION OF IEEE 5 BUS}

The IEEE 5 bus system was selected as a study model, represented by Matlab, as shown in figure 3 .

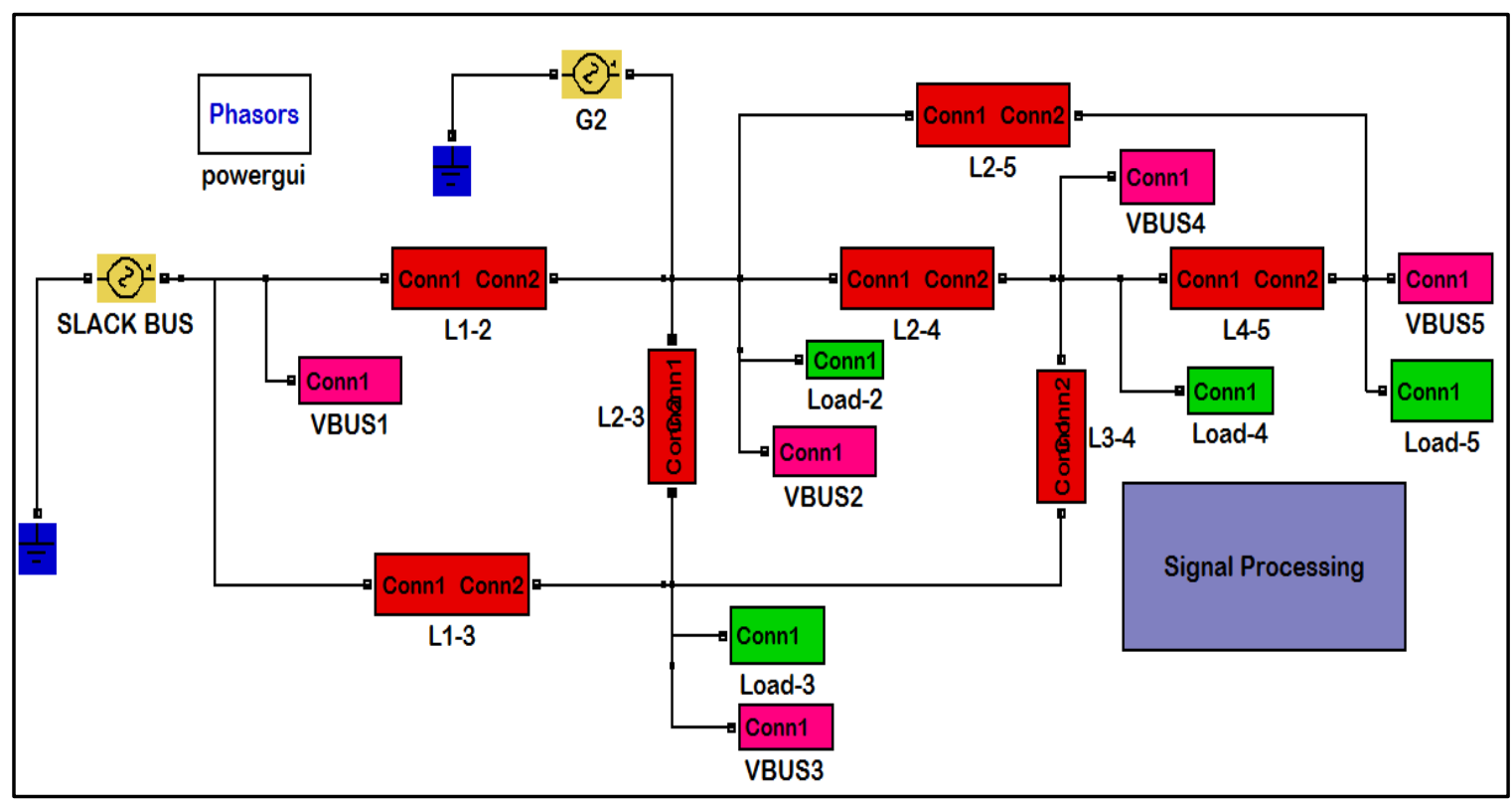

Fig 3: IEEE 5 Bus model

\section{DETERMINATION WEAK LOAD BUS}

The effect of the output of each line on the voltage of the buses was tested for the selected system. $\mathrm{PI}_{\mathrm{V}}$ was calculated at the disconnect of each line individually and sequentially. The worst case was when the fifth line (line2-5) was opened, this was considered the critical line when it was outage for the highest value of $\mathrm{PI}_{\mathrm{V}}$ and drop voltage at bus 5 to the lowest level and the maximum the loading of one of the lines as shown in figure 4 . 


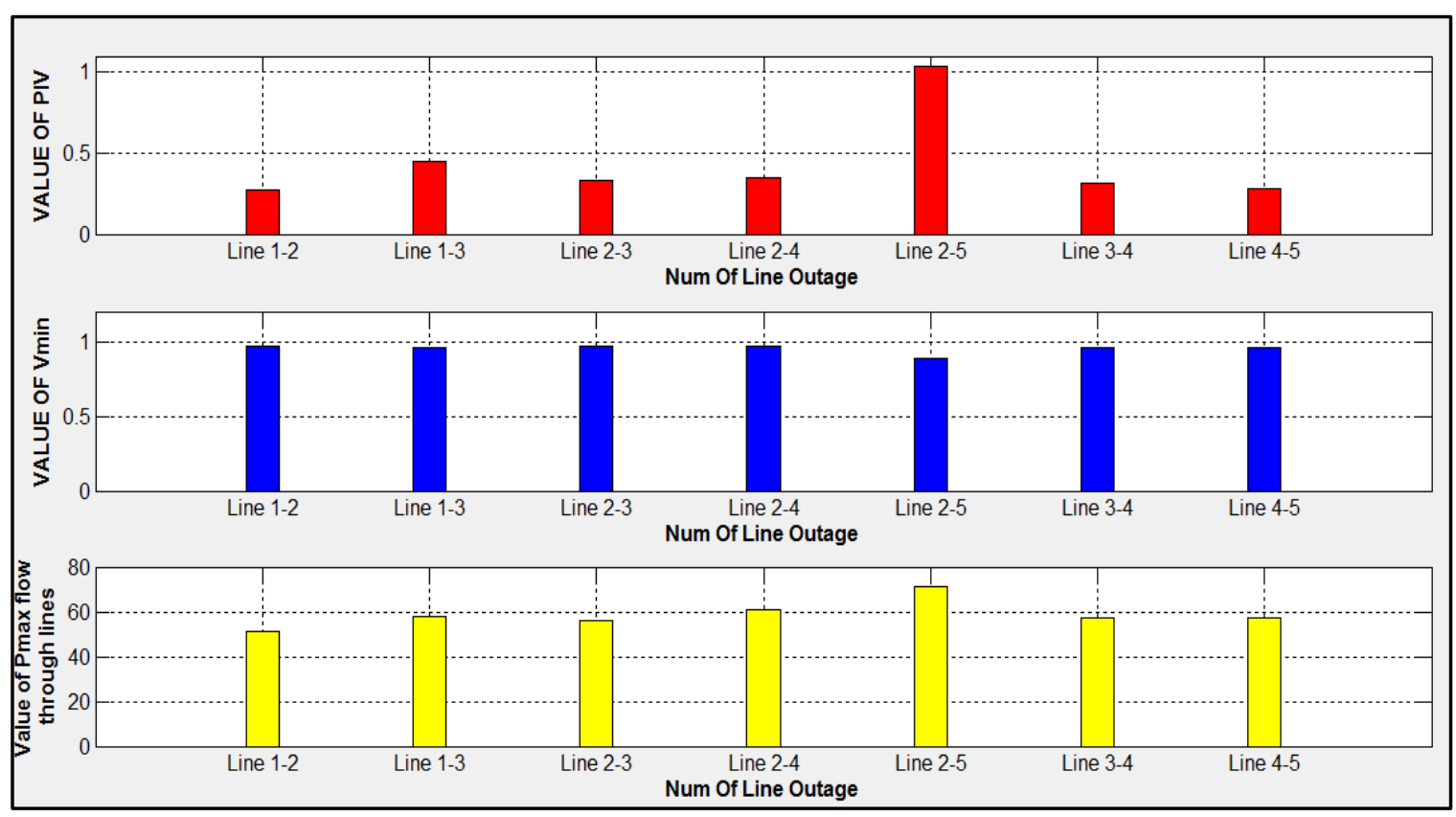

Fig 4: Effect of critical line on bus 5 (weak bus)

\section{LOAD SHEDDING AT BUS 5}

The load at bus 5 was reduced from $0 \%$ (100\% of load as shown in Fig. 5) and to remove $90 \%$ of load (i.e., remaining $10 \%$ of load as shown in Fig. 5). At 30\% of remaining load, the voltage profile is improved, maximum power flow is $45 \%$, PIV is less than 0.4 , so the size of reactive power injected is approximately equal to $70 \%$ of load bus 5 .

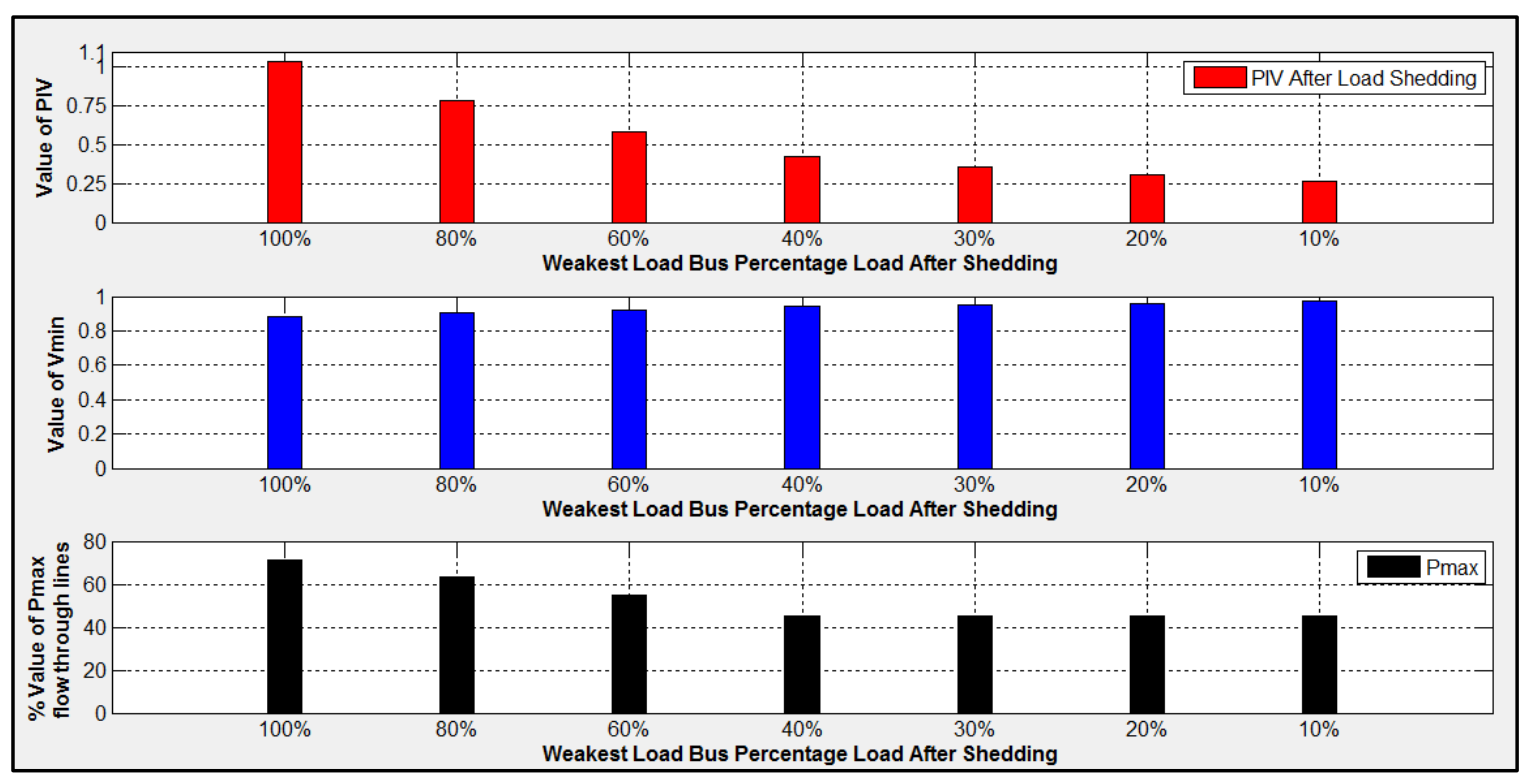

Fig 5: shedding bus load gradually to estimate the injected reactive powe

\section{CONCLUSIONS}

Approximately, the determination of the weakest bus load was determined by the value of $\mathrm{PI}_{\mathrm{V}}$ by disconnecting the lines individually and sequentially in the selected system and thus roughly the location of the injection of reactive power was determined.

$70 \%$ of critical load is the value of the injected reactive power which it was roughly determined by gradually reducing the load at bus 5. It was found that the approximate value to improve the voltages and to fill the deficit in the system to meet the critical load when the line 2-5 outage.

\section{REFERENCES}

[1] Raja Masood Larik, Mohd Wazir Mustafa, Sajid Hussain Qazi, Nayyar Hussain, Shariq Shaikh and Abdul Rauf Bhatti, 2016. "Under Voltage Load Shedding Scheme to Provide Voltage Stability",4th International Conference on Energy, Environment and Sustainable Development.

[2] Aizuriza Ab Aziz, 2014. "Topsis Method for Load Shedding Scheme in Johore System". M.SC. Thesis, Faculty Kejuruteraan Electric and Electronic, University Tun Hussein Onn Malaysia. 
[3] Luiz Augusto Pereira Fernandes, Alexandre Rocco, Heraldo Silveira Barbuy and Geraldo Caixeta Guimarães, 2009. "Electric Power System Under Voltage Load Shedding Protection Can Become a Trap". American Journal of Applied Sciences.

[4] Jeanette Bodi Sorensen \& Anders Pallesen, 20 March 2018." Load Shedding”, Workshop, ENERGINET.

[5] Momen Bahadornejad, 2005. "On Line Local Load Measurement Based Voltage Instability Prediction". $\mathrm{Ph} . \mathrm{D}$. Thesis, Queensland University of Technology.

[6] Prof. dr. Grega Bizjak and Gentrit Rexha, 2018. "Use of capacitors to regulate the voltage in the network". Seminar paper, University of Ljubljana.

[7] Shervin Samimian Tehrani and Peyman Salmanpour Bandaghiri,2014. "Shunt Compensation for Improvement of Voltage Stability Using Static Synchronous Compensator (STATCOM) for Various Faults in Power System". International Journal of Advanced Research in Electrical, Electronics and Instrumentation Engineering.

[8] Amit Kumar Roy,2011. "Contingency Analysis in Power System”, M.Sc. Thesis, Thapar University, Patiala.

[9] Sivarama Karthik Vijapurapu, 2013. "Contingency Analysis of Power Systems in Presence of Geo-
Magnetically Induced Currents", M.Sc. Thesis. Electrical and Computer Engineering. University of Kentucky.

[10] Rohini G D, B Kantharaj and R D Satyanarayana Rao, May-June 2015. "Transmission Line Contingency Analysis in Power system using Fast Decoupled Method for IEEE-14 and IEEE-30 bus Test system", International Journal of Engineering Technology and Management (IJETM), Volume 2, Issue 3.

[11] Dulau Lucian Ioan,2016. "Optimal Power Flow Analysis of IEEE 14 System with Distributed Generators", Journal of Electrical and Electronics Engineering, Volume 9, Number 1 .

[12] Mohd Aidil Bin Ardi,2013. "Power Factor Important in Power System with The Integration of Renewable Energy", M.Sc. Thesis, Faculty of Electrical and Electronic Engineering University Tun Hussein Onn Malaysia.

[13] Godwin Diamenu,2017. "A Review on Stability Improvement of Electric Power Transmission Systems Using Shunt and Series Compensation Techniques", IOSR Journal of Electronics and Communication Engineering (IOSR-JECE), Volume 12, Issue 4, Ver. I 